\title{
A case of immunoglobulin A nephropathy treated successfully with tonsillectomy and steroid pulse therapy 20 years after onset
}

\author{
Jumpei Hasegawa $\cdot$ Kei Yamada $\cdot$ Yoshie Kaga $\cdot$ \\ Yasutomo Abe $\cdot$ Mariko Endo $\cdot$ Sachiko Wakai
}

Received: 20 November 2012/ Accepted: 22 April 2013/Published online: 3 July 2013

(C) The Author(s) 2013. This article is published with open access at Springerlink.com

\begin{abstract}
A 46-year-old male was found to have proteinuria on a routine medical examination in 1985 at the age of 22 years and was diagnosed with immunoglobulin A (IgA) nephropathy by renal biopsy. He regularly visited a hospital, but 3 years later made the decision to stop. In 2000, his serum creatinine level was $1.3 \mathrm{mg} / \mathrm{dl}$. His renal function then deteriorated, with persistent proteinuria and hematuria, following which he visited our hospital in December 2008. A further renal biopsy was performed. Active and chronic IgA nephropathy was confirmed histologically, with sclerosing lesions also being found. He was treated with three courses of steroid pulse therapy in February and tonsillectomy in April 2009. During the follow-up period at the outpatient clinic, results for proteinuria and hematuria were negative, suggesting that progression of renal impairment had been prevented. The efficacy of tonsillectomy plus steroid pulse therapy for early IgA nephropathy has been demonstrated, and this treatment was effective in our patient 20 years after the onset of the disease.
\end{abstract}

Keywords Immunoglobulin A nephropathy .

Tonsillectomy and steroid pulse therapy $\cdot$ Advanced

\section{Introduction}

In 1968, Berger et al. reported that immunoglobulin A (IgA) nephropathy had a favorable prognosis. However, this prognosis was questioned in a report published in

J. Hasegawa $(\bowtie) \cdot$ K. Yamada $\cdot$ Y. Kaga $\cdot$ Y. Abe

M. Endo $\cdot$ S. Wakai

Department of Nephrology, Kidney Center, Ohkubo Hospital,

2-44-1 Kabukicho, Shinjuku-ku, Tokyo 160-8488, Japan

e-mail: bluecat_sora@hotmail.com
1993, which showed that 10-15\% of patients with IgA nephropathy developed end-stage renal disease (ESRD) within 10 years and $40 \%$ after 20 years [1]. The Ministry of Health, Labor and Welfare and Japanese Society of Nephrology considered the disease a matter of great concern and jointly developed the clinical guidelines for IgA nephropathy in Japan (first published in 1995, the second version in 2002 [2] and the third version in 2011 [3]). These clinical guidelines recommend intervention after careful evaluation of disease activity and treatment. These recommendations are based on a report [4] showing that $20 \%$ of patients recovered spontaneously, with $40 \%$ not progressing to renal impairment.

There are several reports on the efficacy of tonsillectomy and steroid pulse therapy for early stage IgA nephropathy [5, 6], although little is known concerning the best treatment for advanced stage IgA nephropathy.

\section{Case report}

A 43-year old male presented with a history of proteinuria discovered on a routine medical examination in 1985 when he was 22 years old. His medical history was acute pancreatitis at age 17 and hypertension at age 40, and the family history indicated that his nephew had $\operatorname{IgA}$ nephropathy. The patient occasionally consumes alcohol, but doesn't smoke. The patient visited a local doctor and underwent a renal biopsy for suspected active nephritis because of the finding (Table 1) of hematuria $3+$ protein from pooled urine $0.78 \mathrm{~g} / \mathrm{day}$ and a plasma creatinine $(\mathrm{Cr})$ level of $1.16 \mathrm{mg} / \mathrm{dl}$ [estimated glomerular filtration rate (eGFR) $71 \mathrm{ml} / \mathrm{min} / 1.73 \mathrm{~m}^{2}$ ]. Pathologic examination revealed IgA nephropathy with partial cellular crescent formation in 1 of the 12 glomeruli, slight mesangial matrix 
Table 1 The clinical course of laboratory findings

\begin{tabular}{|c|c|c|c|c|c|}
\hline & $\begin{array}{l}1985 \text { ( } 22 \text { years old) } \\
\text { First renal biopsy }\end{array}$ & $\begin{array}{l}2000 \text { ( } 35 \text { years old }) \\
\text { Follow-up of local } \\
\text { doctor }\end{array}$ & $\begin{array}{l}2008 \text { ( } 43 \text { years old) } \\
\text { Second renal biopsy }\end{array}$ & $\begin{array}{l}2009 \text { ( } 44 \text { years old) } \\
\text { Clinical remission } \\
7 \text { months after steroid } \\
\text { pulse therapy }\end{array}$ & $\begin{array}{l}2013 \text { (43 years old) } \\
\text { The last outpatient } \\
\text { visit }\end{array}$ \\
\hline Urinary occult blood & $3+$ & - & $3+$ & - & - \\
\hline Urinary & $3+$ & $1+$ & $3+$ & - & - \\
\hline Protein & $0.78 \mathrm{~g} /$ day & ND & $0.90 \mathrm{~g} / \mathrm{gCr}$ & $0.04 \mathrm{~g} / \mathrm{gCr}$ & $0.03 \mathrm{~g} / \mathrm{gCr}$ \\
\hline Serum Cr $(\mathrm{mg} / \mathrm{dl})$ & 1.16 & 1.30 & 1.63 & 1.20 & 1.40 \\
\hline $\mathrm{eGFR}\left(\mathrm{ml} / \mathrm{min} / 1.73 \mathrm{~m}^{2}\right)$ & 71.0 & 48.5 & 38.7 & 53.0 & 45.1 \\
\hline
\end{tabular}

expansion, and mild atrophy of the renal tubule and interstitium. He was followed up without treatment, and the urinary abnormalities resolved spontaneously. He stopped visiting the hospital 3 years after the first visit because of the repeated negative urine analysis and did not visit any other hospital thereafter. He continued to undergo routine medical examinations, which were intermittently positive for microhematuria and proteinuria. His next visit to a medical institution was in 2002 at 38 years of age and revealed urine protein $2+$, urine occult blood $1+$, plasma $\mathrm{Cr} 1.13 \mathrm{mg} / \mathrm{dl}$ and hypertension. An angiotensin receptor blocker (ARB) was started. After that, he saw a doctor regularly, but hematuria and proteinuria became gradually worse. A relapse of $\operatorname{IgA}$ nephropathy was suspected. In March 2009, he was admitted to a hospital for renal biopsy to evaluate the progression of $\operatorname{IgA}$ nephropathy.

The patient's general condition at the time of hospitalization was height $163.0 \mathrm{~cm}$, weight $55.0 \mathrm{~kg}$, body mass index $20.7 \mathrm{~kg} / \mathrm{m}^{2}$, blood pressure $116 / 72 \mathrm{mmHg}$, heart rate 83 beats/min and temperature $36.6{ }^{\circ} \mathrm{C}$. He was lucid with no sign of anemia in the palpebral conjunctiva. No swelling of the throat, abnormal chest auscultation, hard and tender points in the abdominal area or edema of the extremities was observed. Medical examinations (Table 1) revealed urine protein $3+(0.90 \mathrm{~g} /$ day $)$, urine occult blood $3+(\mathrm{RBC}$ 10-19/HPF) and serum $\mathrm{Cr} 1.63 \mathrm{mg} / \mathrm{dl}$.

Renal biopsy (Fig. 1) showed 4 global scleroses, 3 cellular crescent formations and 3 adhesions in 28 glomeruli; moderate expansion of the mesangial matrix; moderate tubular atrophy with mild cell infiltration in the interstitium; and moderate arteriolosclerosis and thickening of interlobular arteries. Immunostaining of $\operatorname{IgA}$ confirmed the diagnosis of active chronic-progressive IgA nephropathy.

After admission, the patient was treated with tonsillectomy and steroid pulse therapy. Steroid pulse therapy was given as follows: methylprednisolone was administered continuously at a pulsed dose of $500 \mathrm{mg} /$ day for 3 days, followed by oral prednisolone at a dose of $30 \mathrm{mg}$ continuously for 3 weeks. After completion of the third course, oral prednisolone was initiated at a dose of $30 \mathrm{mg} / \mathrm{day}$

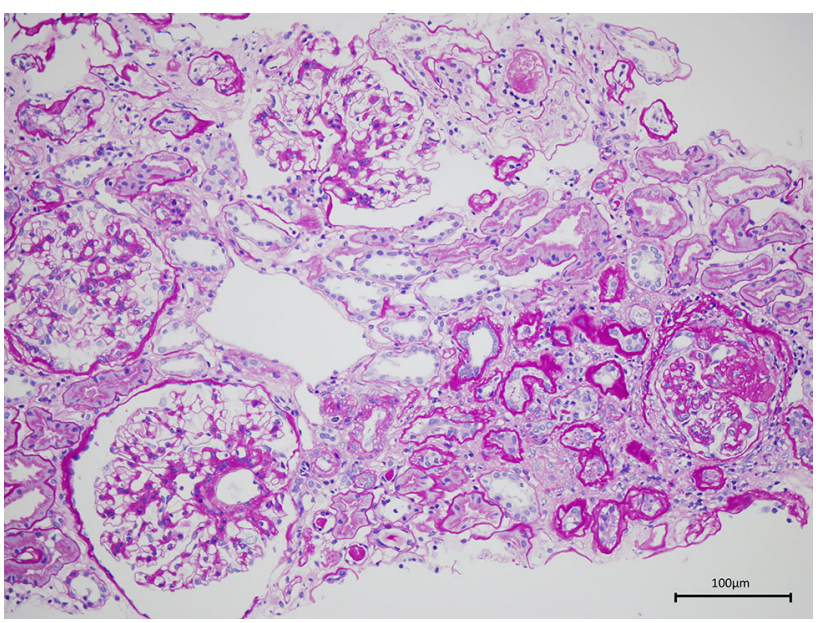

Fig. 1 Renal biopsy findings. PAS staining showed moderate tubular atrophy and globally sclerotic glomeruli

every other day after treatment and tapered by $5 \mathrm{mg}$ every 2 months. The after-treatment follow-up was continued for 1 year. The patient underwent tonsillectomy after discharge from the hospital (day 75) and was then followed up at the outpatient clinic. He completed oral prednisolone treatment in approximately a year, but continued taking an ARB during the follow-up period. Clinical remission was achieved 7 months after the initiation of therapy (Table 1), and hematuria and proteinuria were no longer observed in this 3-year follow-up period (Fig. 2).

\section{Discussion}

It is well known that patients with $\operatorname{IgA}$ nephropathy experience different disease courses. Our patient had a peculiar clinical course. On diagnosis of mild IgA nephropathy and follow-up without treatment, he temporally underwent spontaneous remission, although relapse occurred 14 years later. As a result of his long-term survival with moderate renal failure, the second renal biopsy showed a composite result of more advanced chronic 
Fig. 2 The clinical course

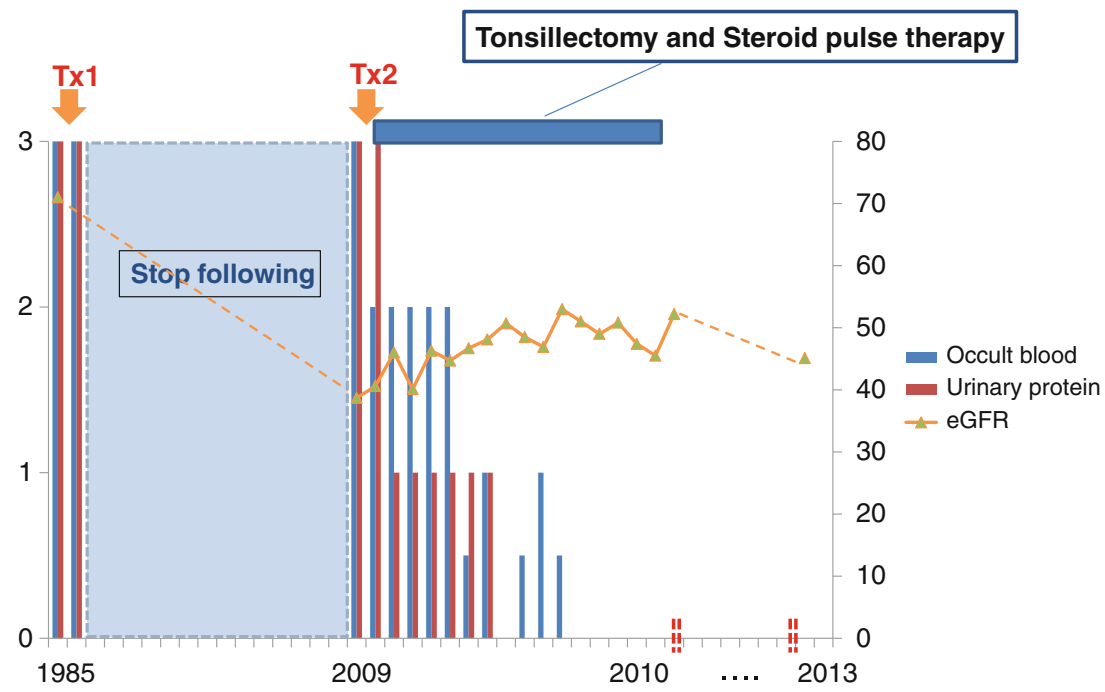

manifestation and active disease with decreased eGFR of $38.7 \mathrm{ml} / \mathrm{min}$.

Since Hotta et al. [7] reported the use of tonsillectomy and steroid pulse therapy in patients with $\operatorname{IgA}$ nephropathy in 2001, the therapy has been used extensively in patients with IgA nephropathy mainly in Japan as well as in other countries. As mentioned above, some patients have spontaneous remission; therefore, the criteria for its use have not yet been established.

There are several reports on the efficacy of tonsillectomy and steroid pulse therapy for nonadvanced IgA nephropathy, especially in Japan [5, 6]. Although the indication of tonsillectomy and steroid pulse therapy remains controversial, it is hypothesized that there is a "point of no return" in progressive IgA nephropathy after which progression to end-stage renal disease (ESRD) becomes inevitable. Studies on treatment for advanced IgA nephropathy include a retrospective cohort study by Sato [7] who investigated 70 patients with baseline serum $\mathrm{Cr}$ of $1.5 \mathrm{mg} / \mathrm{dl}$ or higher, who were assigned to the tonsillectomy and steroid pulse therapy, oral steroid or control groups and followed up for a mean of 5.9 years. The results showed that patients with baseline serum $\mathrm{Cr}$ of $1.5-2.0 \mathrm{mg} /$ $\mathrm{dl}$ in the tonsillectomy and steroid pulse therapy group had decreased progression of ESRD compared with the other two groups, whereas there was no significant difference in the outcome in patients with baseline plasma $\mathrm{Cr}$ of $\geq 2.0 \mathrm{mg} / \mathrm{dl}$. Komatsu et al. [8] reported similar results, indicating that tonsillectomy and steroid pulse therapy are not indicated in patients with a Cr level above $2.0 \mathrm{mg} / \mathrm{dl}$.

Our patient was considered to have a poor prognosis as he had a long disease duration of 24 years and advanced renal impairment with eGFR of $38.7 \mathrm{ml} / \mathrm{min}$ and plasma $\mathrm{Cr}$ of $1.41 \mathrm{mg} / \mathrm{dl}$. However, the $\operatorname{IgA}$ nephropathy continued to present disease activity; therefore, we performed tonsillectomy and steroid pulse therapy. Remission of the urinary findings was achieved, and progressive deterioration of renal function was successfully prevented. Although a chronic manifestation such as glomerulosclerosis remained, eGFR improved following suppression of acute inflammatory symptoms. Hotta et al. [9] reported that tonsillectomy and steroid pulse therapy were associated with histological improvements such as reduced mesangial proliferation and interstitial fibrosis [10]. Subsequent development of nephrosclerosis may be reduced mainly by management of hypertension and nutritional therapy with protein and sodium restriction preventing hyperfiltration in residual glomeruli.

This case report shows the possibility of the effect of tonsillectomy and steroid pulse therapy for $\operatorname{IgA}$ nephropathy with long disease duration and decreased renal function if the activity of IgA nephropathy remains.

Conflict of interest The authors have declared that no conflicts of interest exist.

Open Access This article is distributed under the terms of the Creative Commons Attribution License which permits any use, distribution, and reproduction in any medium, provided the original author(s) and the source are credited.

\section{References}

1. Koyama A, Igarashi M, Kobayashi M. Natural history and risk factors for immunoglobulin A nephropathy in Japan. Research Group on Progressive Renal Diseases. Am J Kidney Dis. 1997;29:526-32.

2. Tomino Y, Sakai H. Clinical guides for immunoglobulin A (IgA) nephropathy in Japan, second version. Jpn J Nephrol. 2002;44(7): 487-93.

3. Clinical guides for immunoglobulin A (IgA) nephropathy in Japan, third version. Jpn J Nephrol 2011;53(2):123-35.

4. Koyama A, Igarashi M, Kobayashi M. Natural history and risk factors for immunoglobulin A nephropathy in Japan. Research Group on Progressive Renal Diseases. Am J Kidney Dis. 1997;29(4):526-32. 
5. Hotta O, Miyazaki M, Furuta T, Tomioka S, Chiba S, Horigome I, Abe K, Taguma Y. Tonsillectomy and steroid pulse therapy significantly impact on clinical remission in patients with IgA Nephropathy. Am J Kidney Dis. 2002;39:736-43.

6. Kawaguchi T, Ieiri N, Yamazaki S, Hayashino Y, Gillespie B, Miyazaki M, Taguma Y, Fukuhara S, Hotta O. Clinical effectiveness of steroid pulse therapy combined with tonsillectomy in patients with immunoglobulin A nephropathy presenting glomerular hematuria and minimal proteinuria. Nephrology (Carlton). 2010;15:116-23.

7. Hotta O, Miyazaki M, Furuta T, Tomioka S, Chiba S, Horigome I, Abe K, Taguma Y. Tonsillectomy and steroid pulse therapy significantly impact on clinical remission in patients with $\operatorname{IgA}$ nephropathy. Am J Kidney Dis. 2001;38(4):736-43.

8. Sato M, Hotta O, Tomioka S, et al. Cohort study of advanced IgA nephropathy: efficacy and limitations of corticosteroids with tonsillectomy. Nephron Clin Pract. 2003;93:c137-45.

9. Komatsu H, Fujimoto S, Sato Y, et al. "Point of No Return (PNR)" in progressive IgA nephropathy: significance of blood pressure and proteinuria management up to PNR. J Nephrol. $2005 ; 18: 690-5$.

10. Hotta O, Furuta T, Chiba S, Tomioka S, Taguma Y. Regression of IgA nephropathy: a repeat biopsy study. Am J Kidney Dis. 2002;39(3):493-502. 